\title{
A practical and ethical solution to the opioid scheduling conundrum
}

This article was published in the following Dove Press journal:

Journal of Pain Research

5 December 2013

Number of times this article has been viewed

\author{
Michael E Schatman' \\ Beth D Darnall ${ }^{2}$ \\ 'Foundation for Ethics in Pain \\ Care, Bellevue, WA, USA; ${ }^{2}$ Stanford \\ University School of Medicine, \\ Division of Pain Medicine, Palo Alto, \\ CA, USA
}

Abuse-deterrent formulations (ADFs) of opioids have been in existence since the $1970 \mathrm{~s},{ }^{1}$ with abuse-deterrent mechanisms including physical barriers (eg, barriers to crushing), chemical additives such as opioid antagonists or irritants, and prodrugs that require conversion of the medication into their active forms in the gastrointestinal tract. ${ }^{2}$ A recent systematic review and meta-analysis ${ }^{3}$ found no difference between ADFs and non-ADFs in terms of efficacy or adverse events including nausea, vomiting, dizziness, headache, somnolence, constipation, and pruritus. Notably, the efficacy of ADFs in preventing abuse is not yet established, and therefore the authors could only comment on their "potential ... to deter or resist some of the common forms of tampering associated with opioid misuse and abuse". While Turk et $\mathrm{al}^{2}$ have elucidated the complexity of producing high-quality research on the efficacy of ADFs to reduce opioid abuse, recent data are encouraging. For example, since Purdue Pharma's (Stamford, CT, USA) voluntary reformulation of OxyContin ${ }^{\circledR}$ to an ADF in 2010, abuse of the medication has decreased significantly. ${ }^{4-6}$ As a specific example, National Poison Data System statistics indicated a $36 \%$ reduction in abuse exposure for OxyContin following ADF reformulation. Meanwhile, researchers for Purdue Pharma found an increase in abuse exposure for other single-entity oxycodone products and a $42 \%$ increase in abuse exposure for heroin during the same time frame. ${ }^{7}$ Although OxyContin has been the most investigated abuse deterrent formulation, ADFs of other opioids have demonstrated promise in preliminary investigations. ${ }^{8,9}$

Data have indicated that despite being home to only $4.6 \%$ of the world's population, the US consumes $80 \%$ of the world's prescription opioid analgesics. ${ }^{10}$ The overreliance of Americans on prescription opioid analgesics for chronic noncancer pain has brought into question the integrity of the nation's pain care system, not just in the US, ${ }^{11}$ but in the eyes of the international pain community. ${ }^{12}$ After more than a decade of problems related to opioid use and misuse (eg, overprescription, fraudulent marketing, ${ }^{13}$ diversion, abuse, overdose deaths ${ }^{14}$ ), and denial of the iatrogenic complications of opioids, ${ }^{15}$ various factions of government have initiated measures to control opioids, measures that have been referred to as the "war on opioids". As is the case in any "war", casualties abound. For instance, the collateral damage associated with reducing access to opioids in the US has been an increase in the abuse of other drugs, often black tar heroin, in people who previously had access to prescription opioids. ${ }^{16}$ Although experts have called for the establishment of a "middle ground", ${ }^{17}$ such a balance has been elusive, especially in the US. 
In the US, drugs are scheduled-based according to the Controlled Substance Act of 1970, which designates drugs into one of five schedules based upon medicinal value, harmfulness, and potential for abuse and addiction. ${ }^{18}$ Schedule I drugs are those considered to have a high potential for abuse with no medicinal value, Schedule II drugs have a high potential for abuse with medicinal value, Schedule III designates drugs that have a lower potential for abuse than Schedule I and II drugs, Schedule IV drugs have a low potential for abuse, and Schedule V drugs are thought to have an abuse potential even lower than those designated as Schedule IV. ${ }^{18}$ The vast majority of opioids prescribed orally for analgesia are classified as Schedule II drugs, with the exceptions being certain codeine compounds and hydrocodone compounds. ${ }^{19}$ Due to a controversial 1971 decision by the US Food and Drug Administration (FDA), hydrocodone was given a "split" Schedule, with pure hydrocodone (which was unavailable in the US until October 2013) designated as a Schedule II and hydrocodone in combination with a nonopioid analgesic (hydrocodone combination drugs) assigned Schedule III status. ${ }^{20}$ The problem with this designation is that there is no evidence that hydrocodone combination drugs are any less abusable than is pure hydrocodone. Accordingly, the FDA convened early in 2013 to consider upscheduling hydrocodone combination drugs from Schedule III to Schedule II. Critics of the potential upscheduling of hydrocodone combination drugs claim that, should this occur, patients and physicians will suffer great inconvenience (as Schedule II drugs require a hard copy prescription and cannot be automatically refilled), resulting in a deleterious impact on pain management. ${ }^{21}$

The scheduling of opioid analgesics in the US does not take into account whether the medication is an ADF or a non-ADF. In fact, all ADFs currently available on the US market are classified as Schedule II drugs. We find this schema of scheduling to lack consistency with the purpose of the scheduling classification system. Presumably, the goal of classifying a drug as Schedule II versus Schedule III is to provide appropriate safety structures, thus creating an abuse deterrent system. Accordingly, one would expect that ADFs would be classified as Schedule II and non-ADFs as Schedule III. Despite efforts to improve risk mitigation within medical practices through opioid agreements, pill counts, urine drug testing, and prescription monitoring programs, the lethality of prescription opioid analgesics in the US has continued to increase, based upon the most recent available Centers for Disease Control data. ${ }^{22}$ Prescription opioid abuse is not likely to simply "go away", and the $16,000+$ prescription opioid-related deaths that occur annually in the $\mathrm{US}^{22}$ are not likely to decrease unless manufacturers and the FDA cooperate in an effort to make all prescription opioids available only as ADFs. Concern regarding the costs of ADFs has been voiced ${ }^{23,24}$ and indeed, the American health insurance industry has at times refused to provide coverage for these potentially life-preserving medications. ${ }^{25}$ ADFs have been posited to have specific value in treating patients at high risk for prescription opioid abuse. ${ }^{26,27}$ However, Stanos et $\mathrm{al}^{28}$ have opined that: "Limiting prescription of tamperresistant opioid formulations to patients assessed to have an elevated risk of abuse may prove ineffective if these patients can obtain traditional prescription opioid formulations from another source."

As opioid prescription increases in other developed and less developed nations as well, ${ }^{29}$ problems with abuse, diversion, and overdoses are increasing in tandem. ${ }^{30}$ The World Health Organization "ladder" for pain relief ${ }^{31}$ also does not take into account abuse-deterrence, and therefore an update to this international classification system should be considered. Indeed, the continued relative ease of access to non-ADFs is a serious international concern that merits examination (and appropriate revision) of existing systems of classification in all nations. This may be accomplished by encouraging a relatively simple and practical scheduling system that appropriately classifies opioids based on each drug's formulation and its associated risk profile. Such a system would create a logical, inverse relationship between opioid access and risk, and thus would optimize patient safety.

\section{Disclosure}

The authors report no conflicts of interest in this work.

\section{References}

1. Katz N. Abuse-deterrent opioid formulations: are they a pipe dream? Curr Rheumatol Rep. 2008;10:11-18.

2. Turk DC, O'Connor AB, Dworkin RH, et al. Research design considerations for clinical studies of abuse-deterrent opioid analgesics: IMMPACT recommendations. Pain. 2012;153:1997-2008.

3. Michna E, Cheng WY, Corves C, et al. Systematic literature review and meta-analysis of the efficacy and safety of prescription opioids, including abuse-deterrent formulations, in non-cancer pain management. Pain Med. September 23, 2013. [Epub ahead of print.]

4. Cicero TJ, Ellis MS, Surratt HL. Effect of abuse-deterrent formulation of OxyContin. N Engl J Med. 2012;367:187-189.

5. Butler SF, Cassidy TA, Chilcoat $\mathrm{H}$, et al. Abuse rates and routes of administration of reformulated extended-release oxycodone: initial findings from a sentinel surveillance sample of individuals assessed for substance abuse treatment. J Pain. 2013;14:351-358.

6. Severtson SG, Bartleson BB, Davis JM, et al. Reduced abuse, therapeutic errors, and diversion following reformulation of extended-release oxycodone in 2010. J Pain. 2013;14:1122-1130.

7. Coplan PM, Kale H, Sandstrom L, Landau C, Chilcoat HD. Changes in oxycodone and heroin exposures in the National Poison Data System after introduction of extended-release oxycodone with abuse-deterrent characteristics. Pharmacoepidemiol Drug Saf. 2013;22(12):1274-1282. 
8. Vosburg SK, Jones JD, Manubay JM, et al. Assessment of a formulation designed to be crush-resistant in prescription opioid abusers. Drug Alcohol Depend. 2012;126:206-215.

9. Vosburg SK, Jones JD, Manuabay JM, et al. A comparison among tapentadol tamper-resistant formulations (TRF) and OxyContin ${ }^{\circledR}$ (nonTRF) in prescription opioid abusers. Addiction. 2013;108:1095-1106.

10. Manchikanti L, Fellows B, Ailinani H, et al. Therapeutic use, abuse, and nonmedical use of opioids: a ten-year perspective. Pain Physician. 2010;13:401-435.

11. Darnall BD, Schatman ME, Argoff CE, Ballantyne JC. Understanding opioids: part 1. Medscape Neurology. January 9, 2013. Available from: http://www.medscape.com/viewarticle/777126. Accessed December 2, 2013.

12. Bannwarth B. Will abuse-deterrent formulations of opioid analgesics be successful in achieving their purpose? Drugs. 2012;72:1713-1723.

13. Frederickson PD. Criminal marketing: corporate and managerial liability in the prescription drug industry. Midwest Law J. 2008;22:115-147.

14. Okie S. A flood of opioids, a rising tide of deaths. $N$ Engl J Med. 2010;363:1981-1985.

15. Schatman ME. The role of the health insurance industry in perpetuating suboptimal pain management: ethical implications. Pain Med. 2011;12: 415-426.

16. Hartrick GT, Gatchel RJ, Conroy S. Identification and management of pain medication abuse and misuse: current state and future directions Expert Rev Neurother. 2012;12:601-610.

17. Harden RN. Chronic pain and opiates: a call for moderation. Arch Phys Med Rehabil. 2008;89 Suppl 1:S72-S76.

18. US Food and Drug Administration. Controlled Substances Act. Available from: http://www.fda.gov/RegulatoryInformation/ Legislation/ucm148726.htm. Accessed October 31, 2013.

19. US Department of Justice Drug Enforcement Administration. Drugs of Abuse, 2011 ed. Available from: http://www.justice.gov/dea/docs/ drugs_of_abuse_2011.pdf. Accessed November 3, 2013.

20. Mehendale AW, Goldman MP, Mehendale RP, Rana K. Opioids: myth versus reality, calling all physicians. J Palliat Care Med. 2013;3:151.
21. Gudin J, Lee AJ. The downside of upscheduling. Pain Med. 2013;14: 1628-1629.

22. Centers for Disease Control and Prevention. Opioids continue to be associated with an increase in drug overdose deaths, February 20, 2013. Available from: http://www.cdc.gov/media/releases/2013/ p0220_drug_overdose_deaths.html. Accessed November 3, 2013.

23. von Gunten CF, Bruera E, Pirrello RD, Portenoy RK. New opioids: expensive distractions or important additions to practice? J Palliat Med. 2010;13:505-511.

24. Mastropietro DJ, Omidian H. Current approaches in tamper-resistant and abuse-deterrent formulations. Drug Dev Ind Pharm. 2013;39: 611-624.

25. Argoff CE, Stanos SP, Wieman MS. Validity testing of patient objections to acceptance of tamper-resistant opioid formulations. J Pain Res. 2013;6:367-373.

26. Brushwood DB, Rich BA, Coleman JJ, et al. Legal liability perspectives on abuse-deterrent opioids in the treatment of chronic pain. J Pain Palliat Care Pharmacother. 2010;24:333-348.

27. Lourenço LM, Matthews M, Jamison RN. Abuse-deterrent and tamperresistant opioids: how valuable are novel formulations in thwarting non-medical use? Expert Opin Drug Deliv. 2013;10:229-240.

28. Stanos SP, Bruckenthal P, Barkin RL. Strategies to reduce the tampering and subsequent abuse of long-acting opioids: potential risks and benefits of formulations with physical or pharmacologic deterrents to tampering. Mayo Clin Proc. 2012;87:683-694.

29. United Nations. Report of the International Narcotics Control Board for 2012. Available from: https://www.incb.org/incb/en/publications/ annual-reports/annual-report-2012.html. Accessed November 3, 2013.

30. Tobin CL, Dobbin M, McAvoy B. Regulatory responses to over-thecounter codeine analgesic misuse in Australia, New Zealand and the United Kingdom. Aust N Z J Public Health. 2013;25:483-488.

31. World Health Organization. WHO's pain ladder for adults. Available from: http://www.who.int/cancer/palliative/painladder/en/. Accessed November 15, 2013.
Journal of Pain Research

\section{Publish your work in this journal}

The Journal of Pain Research is an international, peer-reviewed, open access, online journal that welcomes laboratory and clinical findings in the fields of pain research and the prevention and management of pain. Original research, reviews, symposium reports, hypothesis formation and commentaries are all considered for publication.

\section{Dovepress}

The manuscript management system is completely online and includes a very quick and fair peer-review system, which is all easy to use. Visit http://www.dovepress.com/testimonials.php to read real quotes from published authors. 